\title{
Gender, genetics, and analgesia: understanding the differences in response to pain relief
}

This article was published in the following Dove Press journal: Journal of Pain Research

\author{
Senthil Packiasabapathy \\ Senthilkumar Sadhasivam \\ Department of Anesthesia, Riley \\ Hospital for Children at Indiana \\ University Health, Indianapolis, IN, \\ USA
}

\begin{abstract}
Genetic variations and gender contribute significantly to the large interpatient variations in opioid-related serious adverse effects and differences in pain relief with other analgesics. Opioids are the most commonly used analgesics to relieve moderate-to-severe postoperative pain. Narrow therapeutic index and unexplained large interpatient variations in opioid-related serious adverse effects and analgesia negatively affect optimal perioperative outcomes. In surgical, experimental, chronic, and neuropathic pain models, females have been reported to have more pain than males. This review focuses on literature evidence of differences in pain relief due to multiple genetic variations and gender of the patient.

Keywords: pain, analgesia, pain genomics, pharmacogenomics, pharmacokinetics, pharmacodynamics
\end{abstract}

\section{Introduction}

Individual variation in pain perception and response to analgesics has been a subject of interest for quite some time now. Genetic factors and sex of the patient are associated with differences in analgesia. For instance, the $M C 1 R$ gene, which is associated with fair skin and red hair, has been found to play a role in sexual dimorphism of kappa-opioid analgesia. Red-haired women, with two variants of the $M C 1 R$ allele, showed significantly greater analgesia in response to pentazocine, compared to redhaired men. ${ }^{1}$ This is an example of the role played by chromosomal sex in dissimilar responses to analgesic therapy, secondary to a specific genotype. There have been case reports of life-threatening respiratory depression in response to tramadol, ${ }^{2,3}$ codeine, ${ }^{4}$ and so on, in extensive metabolizers (EMs) of the prodrugs to their respective active forms. There are a number of other factors such as age, body composition, hormonal milieu, comorbid conditions, co-existing pharmacotherapy, past pain experiences, and environmental and psychosocial factors that play a role in the individual variation in the experience of pain and analgesia. Curiosity in this individual variation began ever since the period of Pythagoras, who noticed that some experienced fatal reactions on ingesting fava beans and others did not. ${ }^{5}$ Today, in an era of epigenetic therapies, understanding the genetic and gender differences in drug metabolism and drug response holds extreme significance and it has been facilitated by the successful completion of the human genome project in 2003 .

This review aims to shed light on the gender differences and pharmacogenetics relevant to pain management. Pain is a subjective experience, which includes physical as well as emotional components, and is difficult to measure objectively. Each person
Correspondence: Senthilkumar Sadhasivam

Department of Anesthesia, Riley Hospital for Children at Indiana University Health, RH 2835, 705 Riley Hospital Drive, Indianapolis, IN 46202, USA

Tel + I 3179483845

Fax + I 3179440282

Email ssadhasivam@iuhealth.org 
is unique in perception and response to pain and so is each individual's response to analgesic therapy. The WHO pain ladder, which is a simple yet effective algorithm to manage pain, is nonetheless, an over-generalized management guideline when individual differences are considered. Understanding these differences is the first step toward individualized medicine or tailoring therapy to each individual, or in other words, a step toward an "ideal analgesic therapy".

\section{Gender differences in pain perception}

In order to understand the gender difference in response to pain relief, understanding the gender difference in pain perception is the first essential step. It has been now understood that this difference is due to a multitude of other factors than just the chromosomal sex. Hence, it is more appropriate to address it as "the gender difference", as it encompasses the psychological and social aspects of sex as well. Phenotypic expression of various alleles has more relevance in individual differences in pain perception and analgesic response, rather than just the presence of a distinct genotype, and this expression, in turn, is influenced by a number of other internal and environmental factors.

There are a number of studies that examine the gender differences in pain perception. Though the results are mixed, a majority of them point in the direction of increased sensitivity to pain in females. ${ }^{6}$ Females are at an increased risk of many chronic pain conditions compared to males. The population prevalence of several pain conditions such as migraine, tension headache, irritable bowel syndrome, and fibromyalgia is higher in females. ${ }^{6-9}$

Females also show a higher incidence of acute postoperative pain. ${ }^{6}$ Females are also reported to have an increased sensitivity in a number of experimental pain models. This includes pain induced by electrical, thermal, mechanical, chemical stimuli, or more advanced, clinically relevant pain models such as the temporal summation of pain and conditioned pain modulation (CPM). ${ }^{7}$ Temporal summation measures pain facilitation in response to repeated stimuli over a period of time. CPM measures a decrease in pain perception in response to a "conditioning pain stimulus". It is based on "pain inhibits pain" model and is used to assess endogenous antinociception. Responses are measured in terms of pain intensity scales such as the visual analog scale, self-reported unpleasantness rating, and in terms of threshold and tolerance. Threshold measures the time or intensity of stimulus at which the subject first reports pain perception. Tolerance is the maximum amount of pain stimulus the subject is able to withstand. In general, females display a lower pain threshold and tolerance to painful stimuli compared to males. Women show a greater temporal summation of pain (pain facilitation), whereas men show better pain modulation (pain inhibition). ${ }^{6-9}$ Pain modulation through diffuse noxious inhibitory control (DNIC) has been found more efficient in men than in women. ${ }^{10}$ In a recent review by Hermans et al, nine of the 15 studies that compared CPM between males and females did not find any difference between the genders. The remaining six studies found that males demonstrated better CPM compared to females. ${ }^{11}$ Though evidence of gender difference in CPM is not compelling, those studies that show a difference consistently point toward greater CPM in males.

\section{Causes of gender differences in pain perception}

\section{Sex hormones and neural correlates}

Sex hormones have been known to play a significant role in gender difference in pain perception and analgesia. ${ }^{12}$ Testosterone has been found to decrease pain sensitivity, and a low testosterone state has been demonstrated in many chronic pain conditions, ${ }^{13}$ but the effects of estrogen and progesterone on pain are more complicated, with both pro- and antinociceptive properties. ${ }^{14,15}$ Use of exogenous sex hormones has also been related to an increased risk of chronic pain conditions. ${ }^{16}$ Considering the role of sex hormones in nociception, intragroup variation in pain perception in females and variations in the same individual at various stages of sexual development and cyclical variation with the menstrual cycle hold clinical significance, though the literature evidence is inconsistent. ${ }^{17-20}$ For instance, many studies suggested that females in postovulatory luteal phase show increased pain sensitivity compared to follicular phase. ${ }^{21}$ Pain symptoms in chronic pain conditions seem to be most severe around menstruation, associated with the falling levels of estrogen. ${ }^{17,22}$ Other studies have shown an association between high levels of female reproductive hormones and pain conditions. ${ }^{16,22}$ To add to this controversy, there is a growing body of recent literature, suggesting a lack of variability in pain response across the menstrual cycle. ${ }^{22,23}$ More studies are required to gain further insight.

Age of the individual plays an important role in pain sensitivity and analgesic response due to variation in sex hormone levels and differences in body composition and metabolic ability. Many chronic pain conditions show no difference in prevalence, between genders, and before puberty. ${ }^{12}$ Females show an increased prevalence of these conditions around puberty. ${ }^{24}$ Gender difference in 
cortical pain processing has also been demonstrated. ${ }^{25,26}$ Neuroimaging has demonstrated reduced pain-related activation of CNS antinociceptive pathways in females with low testosterone levels. ${ }^{27}$ Animal studies also show a sexual dimorphism in the anatomy and function of the CNS pain modulatory system. ${ }^{28}$ Midbrain periaqueductal gray (PAG) matter and its descending projections to the rostral ventromedial medulla (RVM) and spinal cord form an important descending antinociceptive pathway. ${ }^{28-31}$ Pain stimulates PAG, resulting in a release of endogenous opioids. Studies in rats showed no qualitative sex difference in the PAGRVM system, but quantitatively, female rats had a greater number of neurons compared to the males. ${ }^{28,32,33}$ On the contrary, functional studies have shown significantly lower activation of PAG-RVM neurons in response to persistent inflammatory pain in female rats compared to male rats. Despite this difference, both male and female rats exhibited similar hyperalgesia after chemically induced inflammatory pain. This suggests the existence of alternative, sex-specific pain-modulating pathways. ${ }^{28}$

Sexual dimorphism has also been observed in mu-opioid receptors (MOR). Males have higher levels of MOR expression and better opioid binding in the rostrocaudal axis of PAG. ${ }^{28}$ This may have an association with increased androgen receptor (AR) expression in PAG neurons. Estradiol, in contrast, has been known to cause MOR internalization and to attenuate neuronal hyperpolarization secondary to MOR activation. ${ }^{34-36}$ Sex difference has also been noticed in the MOR second messenger-signaling cascade. ${ }^{37,38}$

Sex hormones also influence spinal cord pain modulation. ${ }^{39,40}$ When estrogen levels are high, spinal antinociception was robust in female rats and was comparable to males. ${ }^{28}$ This is because estrogen has been found to facilitate heterodimerization of kappa-opioid receptors (KOR) and MOR (KOR/MOR heterodimers), and the KOR binding of opioids plays a significant role in the spinal antinociception in females. ${ }^{41,42}$

Hormonal influence in peripheral pain processing has also been studied, especially in inflammatory pain. ${ }^{43,44}$ Inflammation-induced proinflammatory peptides' release has been found to vary with the phase of the menstrual cycle. $^{45}$

Dimorphism in a number of other pain neurotransmitters and their receptors has also been studied. Some examples include NMDA receptors, ${ }^{46}$ orphanin FQ/nociception, ${ }^{47}$ protein kinases, ${ }^{48}$ toll-like receptor 4 (TLR4), ${ }^{49}$ adenosine receptors ${ }^{50}$ cannabimimetic lipids, ${ }^{51}$ cytokine expression, ${ }^{52}$ monoamine receptors, ${ }^{53}$ neuregulin $1,{ }^{54}$ and neurosteroids.$^{55}$
All the above-discussed gender difference in nociceptive and pain-modulating pathways are significant, since they may also play an important role in sexual dimorphism of opioid analgesia, which is discussed later.

\section{Comorbid conditions}

Females with chronic pain conditions show increased pain facilitation such as temporal summation, and this phenomenon is not seen in males. Increased prevalence of depression and anxiety in females compared to males is also a likely cause of gender difference in pain perception. ${ }^{12}$

\section{Social factors}

Social factors besides genetics and gender differences can influence pain perception significantly. Gender role expectations, stereotypes, and cultural differences in pain-related beliefs play an important role in gender difference in pain across various cultural and ethnic backgrounds. ${ }^{56,57}$ Past life pain experiences and environmental stress have also been shown to influence pain perception. ${ }^{58}$ Childhood abuse has been found to be associated with an increased incidence of chronic pain in adulthood. ${ }^{59}$

\section{Psychological factors}

Behavioral modifications, pain coping strategies, represent the first response in handling pain. Females are known to use a variety of coping mechanisms such as seeking social support, emotion-focused techniques, attention focus, cognitive re-interpretation, and positive self-statement. ${ }^{60,61} \mathrm{Men}$ more frequently engage in problem-focused techniques and behavioral distraction to handle pain. , $60,61^{-6}$

Women are known to catastrophize more than men, and this involves magnification and self-rumination of painrelated information. ${ }^{62,63}$ Catastrophizing is associated with chronic and persistent pain. Men show higher degrees of self-efficacy, which refers to the belief that one can successfully perform a behavior to achieve a goal. ${ }^{64,65}$

Incidences of depression and anxiety differ among males and females, and these psychological factors increase the risk for pain perception and transition from acute pain to chronic pain.

\section{Gender and analgesic response}

The gender differences in drug response can either be pharmacokinetic or pharmacodynamic differences. Body composition and metabolism differ between genders. Sex hormones also influence protein binding and metabolism of various drugs, introducing a pharmacokinetic dimorphism. ${ }^{66,67}$ 
Examples of pharmacodynamic differences include MOR dimorphism and sex hormonal influences on MOR second messenger activation. ${ }^{28}$ The existence of alternate, sexspecific, pain modulating pathways also influences analgesic response. $^{28}$

It is observed that women are more likely to be prescribed analgesic medications especially nonsteroidal anti-inflammatory agents (NSAIDs). ${ }^{68,69}$ Women also use more over the counter analgesics compared to men. ${ }^{70}$ This may reflect a higher prevalence of many inflammatory and chronic pain conditions among women compared to men. Among NSAIDs, men have demonstrated better pain control with ibuprofen, ${ }^{71}$ while women reported better analgesia with ketorolac, ${ }^{72}$ but the abovementioned studies measured response to experimental pain. In an animal study, cyclooxygenase (COX) knockout female mice exhibited reduced joint destruction compared to COX knockout male mice. ${ }^{73}$ Thus, a gender difference in analgesic and anti-inflammatory properties of NSAIDs is possible.

Studies on gender differences in opioids have yielded mixed results. Postoperative morphine consumption has been found to be lower in women compared to men. ${ }^{56}$ Most of these studies examine the dose of opioid consumed, which may also be influenced by the gender-specific differences in the side effect profile of the opioid, rather than the analgesic efficacy itself. Some studies have measured the gender difference in analgesic efficacy of morphine. Some of them reported better morphine analgesia in women, some reported in men, and others reported no gender difference. ${ }^{12}$ There are some animal studies that report a greater degree of morphine analgesia in males. ${ }^{28}$ There are a number of factors contributing to the above finding.

The dimorphism of PAG-RVM pain modulation pathway has been already discussed. Morphine-induced activation of PAG-RVM neurons was significantly higher in males. ${ }^{28}$ Effects of sex hormones on MOR have also been discussed. Morphine, in addition to its action on MOR, has also been found to act on TLR4 of glial cells, inducing a neuroinflammatory response, which directly opposes morphine analgesia. More active innate immunity and a greater degree of TLR4 expression in females may be another reason for the gender difference in morphine analgesia. ${ }^{49}$

Women are shown to experience better analgesia in response to mixed action opioids such as butorphanol, nalbuphine, and pentazocine. ${ }^{56}$ One significant example is the gene-sex interaction involving the melanocortin receptor (MC1R) gene. ${ }^{1}$ Red-haired, fair-skinned women with two allelic variants of the MC1R gene demonstrated better analgesia from pentazocine compared to red-haired men and women who did not have the allelic variants.

Females also showed an increased incidence of opioidrelated adverse effects such as respiratory depression and postoperative nausea and vomiting (PONV) compared to males. ${ }^{74}$ Prepubertal girls have been shown to have a greater incidence of PONV and respiratory depression after tonsillectomy at higher morphine doses compared to boys. ${ }^{75}$ This unequal burden of adverse effects can contribute to lower opioid consumption in females.

Differences in analgesic response to antiepileptic and antidepressant medications are not widely studied. There is one study that reported no gender difference in analgesic efficacy of paroxetine. ${ }^{76}$ Knowledge about gender difference in response to regional analgesic modalities is also limited. From the above discussion, it becomes clear that there is no strong evidence that would support a gender-specific analgesic intervention in most clinical situations, at present.

\section{Genetic differences in pain and analgesia}

Each person is unique in the way he/she responds to pain; similarly, response to analgesic therapy also immensely varies with each individual. Race of an individual imposes an unequal burden of postoperative pain and adverse effects to analgesics. One observational study showed that Caucasian children have less postoperative pain and a higher incidence of opioid-related adverse effects after tonsillectomy. ${ }^{77}$ Another study reported that Asian Americans have a lower pain threshold and tolerance to experimental pain compared to non-Hispanic Whites. ${ }^{78}$ In a recent review of the literature on racial differences in experimental pain, it was concluded that ethnic minorities such as African Americans and Hispanics showed lower tolerance and greater unpleasantness scores for suprathreshold pain stimuli compared to non-Hispanic Whites. There was no strong evidence of a racial difference in pain threshold. The authors concluded that the difference in tolerance and pain ratings in the suprathreshold range is relevant to clinical pain experience and more research is required in exploring the biopsychosocial factors that cause this difference. ${ }^{79}$ These demonstrate the role of genetic variation (genetic ancestry) along with psychosocial and environmental factors and life experiences in shaping an individual's pain experience.

The same drug at the same dosage may cause therapeutic effects in some and adverse drug effects in the others, while some others may experience no effect at all. This wide range of variability is in part due to genetic variability. The conventional analgesic regime that is based on the type of pain, its 
intensity, age, and body weight of the person does not take into account this genetic variability, thus introducing a huge factor of uncertainty. Pharmacogenomics may have a big role in the dawn of the era of personalized medicine, tailored to meet the individual patient's profile, thereby ensuring better efficacy and absolute safety.

The molecular basis of this variability includes a number of genetic variants. ${ }^{80}$ The most common genetic variant is the single-nucleotide polymorphism (SNP), which represents the alteration in one single base in the DNA fragments. Deletion or insertion of single or multiple base pairs, continuous repeats of 2-4 bases (variable number tandem repeats [VNTR]), repeats of longer DNA fragments (micro- and minisatellites), repeats of larger DNA fragments or the whole genes (copy number variants $[\mathrm{CNV}]$ ), and chromosomal aberrations constitute the other genetic variants. These variants, under multiple influences, express themselves resulting in the unique phenotype. This is effected via the change in structure or function or level of expression of various proteins, including enzymes, transport proteins, receptors, and second messenger systems.

\section{Functional pain genomics}

Genetic variability in the field of pain includes functional pain genomics and pharmacogenomics. ${ }^{80}$ Functional pain genomics explains the individual risk of developing pain, pain intensity, intrinsic pain modulation, and individual response to pain. Some examples include genetic conditions such as congenital insensitivity to pain, ${ }^{81}$ channelopathy-associated insensitivity to pain, ${ }^{82}$ and primary erythromelalgia. ${ }^{83}$ There are few other single-gene pain disorders. The above conditions are very rare, but understanding the pathophysiology of the above conditions may open new targets for analgesic drug therapy and for genetic intervention in pain management. ${ }^{84}$ For example, black mamba venom has been found to abolish pain by its action on acid-sensing ion channels. ${ }^{85}$ Another clinically relevant finding is the existence of polymorphism in minor A allele of SCN9A rs6746030 gene, causing altered pain threshold, resulting in individuals to experience different amounts of pain, in response to standard nociceptive stimulus. ${ }^{86}$ This is important because pain intensity is usually a major factor dictating choice and dosage of analgesics.

Individual differences in pain sensitivity and perception may be partly explained by differences in nociceptive pathways. Catecholamines, such as norepinephrine and dopamine, play a vital role in these pathways, and CNS dopamine levels are related to the production of endogenous opioids that modulate pain. Genetic variability of the COMT gene, which codes for catechol- $O$-methyl transferase (COMT), an enzyme that degrades catecholamines in the CNS, has been found to play a role in individual pain perception. ${ }^{87,88}$ Similarly, a number of other gene polymorphisms are linked to individual pain sensitivity. These include genes coding for GTP cyclohydrolase 1 (GCH1), ${ }^{89}$ estrogen receptor (ESRl), MOR (OPRMI),${ }^{90}$ neurotropin tyrosine kinase receptor type 1 (NTRK1), nerve growth factor $\beta(N G F \beta),{ }^{91}$ and so on.

Another area involving functional genomics in pain perception is the role of psychological factors in pain experience, especially chronic pain. In a study, the presence of a certain polymorphism in the promoter region of the serotonin transporter gene 5-HTTLPR has been found to correlate with neurotic behavior, high levels of anxiety, self-doubt, and negative emotions. ${ }^{92}$ The abovementioned personality traits cause inability to cope with negative emotions associated with pain, resulting in catastrophizing. ${ }^{84}$ Similarly, serotonin (5HT) is involved in the modulation of depression. Persons with certain alleles of $5 H T R 1 A$ and $5 H T R 2 A$ (serotonin receptors) are found to show a higher incidence of postoperative depression and pain. ${ }^{93}$

\section{Pharmacogenomics}

Pharmacogenomics is the study of genetic variabilities that underlie variations in drug response. These variations may be pharmacokinetic or pharmacodynamic differences. In general, pharmacokinetic variability is seen at two levels, either at the conversion of the prodrug to its active form or at the elimination of the active drug. Other areas of pharmacokinetic variability include protein binding of the drug and the transmembrane transport of the drug, which determine the effect site concentration of the drug. Pharmacodynamic variations occur at receptor binding, and second messenger activation, that occurs after receptor binding.

\section{Pharmacokinetics}

The metabolism of drugs occurs in two phases. Phase I involves oxidation, reduction, hydrolysis, and so on. Phase II involves conjugation of substrates to form water-soluble products. Majority of the Phase I enzymes belong to the cytochrome P 450 (CYP450) family, which is responsible for the metabolism of over $80 \%$ of all therapeutic drugs. ${ }^{94}$ Some of the notable subfamilies include CYP2D6 and CYP2C9.

CYP2D6 enzymes metabolize over $20 \%$ of all currently available drugs and are subject to over 100-fold genetic variability in their expression and level of activity. ${ }^{94}$ There are more than $100 \mathrm{CYP} 2 \mathrm{D} 6$ alleles identified that occur in varying frequencies in various ethnic groups. ${ }^{80}$ Based on the 
allelic combinations and variants, patients can be categorized under the following four phenotypic groups: poor metabolizers (PMs), intermediate metabolizers (IMs), extensive metabolisers (EMs), and ultrarapid metabolizers (UMs). Codeine is a widely used opioid, which undergoes CYP2D6-mediated O-demethylation to form its active drug morphine. Codeine itself is a prodrug, with lower affinity and intrinsic activity on MOR. PMs produce very low amounts of morphine, while UM produce excessive amounts of morphine. Therefore, PMs show no or subnormal therapeutic response to codeine, while UMs exhibit significant adverse effects including respiratory depression, excessive sedation, and vomiting. There are many case reports of codeine-induced respiratory depression and deaths in UMs, especially in children and in breast-fed neonates after maternal codeine administration., ${ }^{4,95-98}$ This has led to the US Food and Drug Administration's warning against the prescription of codeine in nursing mothers ${ }^{94}$ and children undergoing tonsillectomy surgery. The Clinical Pharmacogenetics Implementation Consortium (CPIC) has published dosing guidelines for codeine and other opioids based on CYP2D6 genotype, which will be discussed later.

Tramadol is another CYP2D6 substrate and is transformed into its active metabolite $O$-desmethyltramadol. Though tramadol itself has some analgesic action via its action on MOR and nonopioid serotonin, noradrenalinemediated CNS antinociceptive pathways, the major analgesic action is via $O$-desmethyltramadol. Hence, the phenotype of CYP2D6 plays a major role in an individual's analgesic response to tramadol. ${ }^{99,100}$ Respiratory depression has been reported in UMs after tramadol administration. ${ }^{2}$

Another example is genetically variable CYP3A system involved in the conversion of parecoxib to valdecoxib. ${ }^{80}$ Tricyclic antidepressants such as amitriptyline are used as co-analgesics especially in chronic pain. They undergo activation in the liver, which occurs in the following two steps: CYP2D6 hydroxylation and CYP2C19 demethylation. CYP2D6 PMs have higher blood concentrations of cyclic antidepressants, hence, an increased incidence of side effects such as arrhythmia and myelosuppression. ${ }^{101}$

Uridine diphosphate glucuronosyltransferase (UGT) belongs to a group of Phase II enzymes involved in conjugation reactions. Morphine is a substrate of UGT2B7 in the liver and is conjugated to two metabolites such as morphine 3 glucuronide (M3G) and morphine 6 glucuronide (M6G). ${ }^{102}$ $\mathrm{M} 3 \mathrm{G}$ forms $75-85 \%$ of the metabolites and is pharmacologically inactive. M6G is the minor metabolite (5-10\%) and is a potent analgesic. A number of polymorphisms of the UGT enzyme have been identified. Altered response to morphine in relation to specific UGT genotypes has been observed in various studies. ${ }^{103,104}$ Similarly, methadone, fentanyl, alfentanil, and sufentanil elimination are subject to genetic variability in the CYP3A enzyme system. ${ }^{105,106}$

NSAIDs are widely used nonopioid analgesics, alone or as part of a multimodal analgesic regimen. They are metabolized and eliminated by the CYP2C9 enzyme system, which has been known to show a wide genetic variability. PMs show decreased clearance and increased incidence of NSAID toxicity, especially gastrointestinal bleeding. ${ }^{107-110}$ CYP2C9 is also involved in warfarin metabolism, allelic variants that decrease the clearance of warfarin and increase bleeding risk, which is compounded when NSAIDs are prescribed alongside warfarin in patients carrying these variants. ${ }^{111}$

The P-glycoprotein ABCB1/MDR1 transporter is an ATP-dependent efflux transporter found in various tissues. It greatly affects the plasma and effect site concentrations of the substrate drugs. The $A B C B 1$ gene is highly polymorphic. Morphine is a P-glycoprotein substrate, which transports morphine out across the blood-brain barrier, hence decreases CSF concentration of morphine. Hence, genetic variability in $A B C B 1$ may be responsible for morphine-induced respiratory depression and the significant variability in analgesic response to morphine. ${ }^{112}$ There is also a study showing prolonged respiratory depression after fentanyl administration in certain $A B C B 1 / M D R 1$ genotypes. ${ }^{113,114}$

Hepatic cellular uptake of morphine is mediated through organic cation transporter (OCT1), and efflux of $\mathrm{M} 3 \mathrm{G}$ and M6G is mediated through ABCC3. Genetic polymorphism in OCT1 has also been studied. ${ }^{115}$

\section{Pharmacodynamics}

Drugs interact with their specific receptors and initiate a cascade involving the second messenger system, finally culminating in the drug effect. The components in this cascade are subject to genetic variability resulting in variable responses.

MOR belongs to a family of 7-transmembrane G-proteincoupled receptors (GPCR). OPRM1 gene coding for MOR is highly polymorphic, and there are case reports of OPRM1 variants with significantly decreased analgesic response to opioids and greater postoperative opioid requirements. ${ }^{116,117}$ There are many studies on genetic variability of MOR and its relation to pain, but the results are inconsistent. ${ }^{118,119}$

Nonfunctional variants of the $M C 1 R$ gene, which results in red hair and fair skin, are associated with sexual dimorphism in kappa-opioid responses. Red-haired women with these $M C 1 R$ variants are known to require a lesser dose of drugs such as pentazocine compared to red-haired men. ${ }^{1,120}$ 
NSAIDs act through the inhibition of COX pathways. Prostaglandin-endoperoxide synthase (PTGS) 1 and 2 code for COX 1 and 2, respectively. Genetic variations in these enzymes can result in an altered NSAID response. ${ }^{121}$ Individuals with an increased expression of PTGS 2 and hence COX 2 experience better analgesic response to COX 2-specific agents such as celecoxib, while lower levels of expression of COX 2 result in better analgesic response to nonselective NSAIDs. ${ }^{84}$

COMT degrades neurotransmitters such as epinephrine, norepinephrine, and dopamine, which play an integral role in CNS pain pathways. Increased dopamine suppresses the production of endogenous opioid peptides, which in turn upregulates opioid receptor levels and hence altered response to opioids. Genetic variability in COMT expression has been related to variability in opioid dose requirements. ${ }^{122-124}$

Local anesthetics are sodium channel inhibitors; hence, genetic variations in sodium channels may be expected to alter local anesthetic binding and response. This has been proven by in vitro studies showing greater resistance to lidocaine in certain mutations of the $S C N 9 A$ gene coding for sodium channels. ${ }^{125}$ This has also been linked to increased susceptibility to local anesthetic toxicity. ${ }^{126}$

Apart from pharmacokinetic and pharmacodynamic variabilities in drug responses, genetic variability in immunemediated drug hypersensitivity has been studied. Antiepileptics are increasingly used in the management of chronic pain and neuropathic pain. These anticonvulsants commonly cause cutaneous adverse drug reactions including fatal ones such as Stevens-Johnsons syndrome (SJS) and toxic epidermal necrolysis (TEN). ${ }^{127}$ These reactions are HLA-mediated immune reactions, and incidence of these adverse reactions is closely linked to specific HLA alleles. ${ }^{128-131}$

\section{Clinical application of pain genomics}

The CPIC has put forth dosing guidelines based on pharmacogenetic variations for various drugs. There are dosing guidelines for codeine based on CYP2D6 genotype. ${ }^{132}$ For PMs, it is suggested to consider other opioids such as morphine, NSAIDs, and acetaminophen because of no or suboptimal analgesic response to codeine therapy. Alternative analgesics need to be considered for UMs as codeine and tramadol are expected to cause significant and lifethreatening opioid adverse effects including respiratory depression and death.

Based on the CYP2C9 genotype, half the lowest recommended doses of NSAIDs have to be started for PM, in order to avoid complications such as gastrointestinal bleeding. ${ }^{127}$
Similarly, based on CYP2D6 genotype, doses of tricyclics used for chronic pain are to be reduced by $60 \%$ to avoid arrhythmias and myelosuppression in PMs. ${ }^{127}$

Knowledge on functional pain genomics and epigenetic modifications have opened new avenues for pain therapy. Epigenetics refers to the functional genetic changes, not directly involving changes in the nucleotide sequence of the gene but involving increase or decrease in the expression of gene, in response to environmental or developmental cues. ${ }^{94}$ These changes are effected by dynamic, reversible chemical modification of the genome and are involved in differential gene expression throughout life. Some examples include DNA methylation regulated by DNA methyltransferases and histone acetylation regulated by histone deacetylases (HDAC). Poorly managed acute pain is known to increase pain sensitivity and the risk of chronic pain states, and epigenetic modifications are found to play an important role in this process. ${ }^{94}$ Drugs that target enzymes responsible for epigenetic variations are under development. In an animal pain model, DNA methyltransferase inhibitor, zebularine, has been found to reduce pain sensitivity. ${ }^{133,134}$ Similar studies have been done on animal models using HDAC inhibitors as well. ${ }^{135}$ Valproic acid, an HDAC inhibitor, has been found to improve pain scores in humans with type II diabetes mellitus. ${ }^{136}$

Another potential development in the field of pain is the gene therapy, which involves the use of viral vectors, which are used to introduce a promoter sequence in the host cells, which drives the gene expression of interest. This allows a persistent expression of a protein-based endogenous analgesic agent at the site of action. ${ }^{94}$ This can significantly reduce the side effects of pharmacotherapy, but an inadequate expression of the transgene and immune elimination of the vector virus are the limitations. ${ }^{137}$ Nonviral insertion techniques are being studied to overcome these problems. ${ }^{137} \mathrm{~A}$ study has been done in cancer patients, involving the PENK gene, encoding for preproenkephalin, which is the precursor of 6-met-enkephalin and 1-leu-enkephalin, which are endogenous delta-opioid receptor ligands. The highest virus groups have reported $50 \%$ lower pain on numerical rating scale. ${ }^{138}$

\section{Conclusion}

There is a lack of robust evidence to support a gender-specific analgesic management. Intragroup variations in pain perception at various stages of sexual development and a wide range of individual variations seem to be more clinically relevant than a broader gender categorization. Clinical application of genetic knowledge in pain management is still primitive due 
to both existing knowledge gaps and the cost and access constraints. Urine drug testing is a commonly used tool for therapeutic monitoring. The qualitative tests have a high incidence of both false positives and false negatives. The quantitative assays are affected by a number of factors including the volume status and renal function of the patient. It poorly reflects the plasma drug level and the effect site concentration. ${ }^{94}$ The plasma drug level monitoring using mass spectrometry is a more reliable tool for therapeutic monitoring, ${ }^{94}$ but it does not give any idea about the pharmacodynamics of the drug. Genetic testing is still not widely adopted due to accessibility and questionable cost-effectiveness. Currently, genetic testing on oral, buccal mucosal samples has been clinically validated and also economically feasible; several SNPs are readily available for clinical use. ${ }^{139}$ With increasing number of studies on pain genetics and genome-wide association studies (GWAS) on pain underway, widespread genetic testing is likely to become more practical and widely accessible in future. Personalized management algorithms for different pain models, taking into account the gender and multiple genetic variations, along with other contributing factors seem to be a reality in near future.

\section{Disclosure}

The authors report no conflicts of interest in this work.

\section{References}

1. Mogil JS, Wilson SG, Chesler EJ, et al. The melanocortin-1 receptor gene mediates female-specific mechanisms of analgesia in mice and humans. Proc Natl Acad Sci U S A. 2003;100(8):4867-4872.

2. Stamer UM, Stüber F, Muders T, Musshoff F. Respiratory depression with tramadol in a patient with renal impairment and CYP2D6 gene duplication. Anesth Analg. 2008;107(3):926-929.

3. Kirchheiner J, Keulen JT, Bauer S, Roots I, Brockmöller J. Effects of the CYP2D6 gene duplication on the pharmacokinetics and pharmacodynamics of tramadol. J Clin Psychopharmacol. 2008;28(1): $78-83$.

4. Gasche Y, Daali Y, Fathi M, et al. Codeine intoxication associated with ultrarapid CYP2D6 metabolism. $N$ Engl J Med. 2004;351(27):2827-2831.

5. Pirmohamed M. Pharmacogenetics and pharmacogenomics. Br JClin Pharmacol. 2001;52(4):345-347.

6. Fillingim RB, King CD, Ribeiro-Dasilva MC, Rahim-Williams B, Riley JL, 3rd. Sex, gender, and pain: a review of recent clinical and experimental findings. J Pain. 2009;10(5):447-485.

7. Paller CJ, Campbell CM, Edwards RR, Dobs AS. Sex-Based Differences in Pain Perception and Treatment. Pain Med. 2009;10(2): 289-299.

8. Mogil JS. Sex differences in pain and pain inhibition: multiple explanations of a controversial phenomenon. Nat Rev Neurosci. 2012;13(12):859-866.

9. Fillingim RB, Maixner W, Amodei N, et al. Gender differences in the responses to noxious stimuli. Pain Forum. 1995;4(4):209-221.

10. Popescu A, Leresche L, Truelove EL, Drangsholt MT. Gender differences in pain modulation by diffuse noxious inhibitory controls: A systematic review. Pain. 2010;150(2):309-318.
11. Hermans L, Van Oosterwijck J, Goubert D, et al. Inventory of Personal Factors Influencing Conditioned Pain Modulation in Healthy People: A Systematic Literature Review. Pain Pract. 2016;16(6):758-769.

12. Greenspan JD, Craft RM, Leresche L, et al. Studying sex and gender differences in pain and analgesia: A consensus report. Pain. 2007;132:S26-S45.

13. Cairns BE, Gazerani P. Sex-related differences in pain. Maturitas. 2009;63(4):292-296.

14. Craft RM. Modulation of pain by estrogens. Pain. 2007;132:S3-S12.

15. Smith YR, Stohler CS, Nichols TE, Bueller JA, Koeppe RA, Zubieta J-K. Pronociceptive and Antinociceptive Effects of Estradiol through Endogenous Opioid Neurotransmission in Women. Journal of Neuroscience. 2006;26(21):5777-5785.

16. Leresche L, Saunders K, von Korff MR, Barlow W, Dworkin SF. Use of exogenous hormones and risk of temporomandibular disorder pain. Pain. 1997;69(1):153-160.

17. Leresche L, Mancl L, Sherman JJ, Gandara B, Dworkin SF. Changes in temporomandibular pain and other symptoms across the menstrual cycle. Pain. 2003;106(3):253-261.

18. Sherman JJ, Leresche L, Mancl LA, Huggins K, Sage JC, Dworkin SF. Cyclic effects on experimental pain response in women with temporomandibular disorders. J Orofac Pain. 2005;19(2):133-143.

19. Sherman JJ, Leresche L. Does experimental pain response vary across the menstrual cycle? A methodological review. Am J Physiol Regul Integr Comp Physiol. 2006;291(2):R245-R256.

20. Klatzkin RR, Mechlin B, Girdler SS. Menstrual cycle phase does not influence gender differences in experimental pain sensitivity. Eur $J$ Pain. 2010;14(1):77-82.

21. Riley JL 3rd, Robinson ME, Wise EA, Price DD. A meta-analytic review of pain perception across the menstrual cycle. Pain. 1999;81(3): 225-235.

22. Iacovides S, Avidon I, Baker FC. Does pain vary across the menstrual cycle? A review. Eur J Pain. 2015;19(10):1389-1405.

23. Balter JE, Molner JL, Kohrt WM, Maluf KS. Mechanical pain sensitivity and the severity of chronic neck pain and disability are not modulated across the menstrual cycle. J Pain. 2013;14(11):1450-1459.

24. Leresche L, Mancl LA, Drangsholt MT, Saunders K, Korff MV. Relationship of pain and symptoms to pubertal development in adolescents. Pain. 2005;118(1):201-209.

25. Berman S, Munakata J, Naliboff BD, et al. Gender differences in regional brain response to visceral pressure in IBS patients. Eur $J$ Pain. 2000;4(2):157-172.

26. Kern MK, Jaradeh S, Arndorfer RC, Jesmanowicz A, Hyde J, Shaker R. Gender differences in cortical representation of rectal distension in healthy humans. Am J Physiol Gastrointest Liver Physiol. 2001;281(6):G1512-G1523.

27. Vincent K, Warnaby C, Stagg CJ, Moore J, Kennedy S, Tracey I. Brain imaging reveals that engagement of descending inhibitory pain pathways in healthy women in a low endogenous estradiol state varies with testosterone. Pain. 2013;154(4):515-524.

28. Loyd DR, Murphy AZ. The neuroanatomy of sexual dimorphism in opioid analgesia. Exp Neurol. 2014;259:57-63.

29. Basbaum AI, Fields HL. Endogenous pain control mechanisms: review and hypothesis. Ann Neurol. 1978;4(5):451-462.

30. Basbaum AI, Fields HL. Endogenous pain control systems: brainstem spinal pathways and endorphin circuitry. Annu Rev Neurosci. 1984;7(1):309-338.

31. Behbehani MM. Functional characteristics of the midbrain periaqueductal gray. Prog Neurobiol. 1995;46(6):575-605.

32. Kalyuzhny AE, Arvidsson U, Wu W, Wessendorf MW. mu-Opioid and delta-opioid receptors are expressed in brainstem antinociceptive circuits: studies using immunocytochemistry and retrograde tract-tracing. J Neurosci. 1996;16(20):6490-6503.

33. Loyd DR, Murphy AZ. Sex differences in the anatomical and functional organization of the periaqueductal gray-rostral ventromedial medullary pathway in the rat: a potential circuit mediating the sexually dimorphic actions of morphine. J Comp Neurol. 2006;496(5):723-738. 
34. Eckersell CB, Popper P, Micevych PE. Estrogen-induced alteration of mu-opioid receptor immunoreactivity in the medial preoptic nucleus and medial amygdala. $J$ Neurosci. 1998;18(10):3967-3976.

35. Kelly MJ, Qiu J, Rønnekleiv OK. Estrogen modulation of G-proteincoupled receptor activation of potassium channels in the central nervous system. Ann NY Acad Sci. 2003;1007(1):6-9.

36. Micevych PE, Rissman EF, Gustafsson JA, Sinchak K. Estrogen receptor-alpha is required for estrogen-induced mu-opioid receptor internalization. $J$ Neurosci Res. 2003;71(6):802-810.

37. Burstein SR, Williams TJ, Lane DA, et al. The influences of reproductive status and acute stress on the levels of phosphorylated delta opioid receptor immunoreactivity in rat hippocampus. Brain Res. 2013;1518:71-81.

38. Mitrovic I, Margeta-Mitrovic M, Bader S, Stoffel M, Jan LY, Basbaum AI. Contribution of GIRK2-mediated postsynaptic signaling to opiate and 2-adrenergic analgesia and analgesic sex differences. Proc Natl Acad Sci U S A. 2003;100(1):271-276.

39. Papka RE, Storey-Workley M, Shughrue PJ, et al. Estrogen receptor- $\alpha$ and $-\beta$ immunoreactivity and mRNA in neurons of sensory and autonomic ganglia and spinal cord. Cell Tissue Res. 2001;304(2): 193-214.

40. Liu NJ, Gintzler AR. Spinal Endomorphin 2 Antinociception and the Mechanisms That Produce It Are Both Sex- and Stage of Estrus Cycle-Dependent in Rats. Pain. 2013;14(11):1522-1530.

41. Chakrabarti S, Liu NJ, Gintzler AR. Formation of $\mu-/-\kappa$ opioid receptor heterodimer is sex-dependent and mediates female-specific opioid analgesia. Proc Natl Acad Sci U S A. 2010;107(46):20115-20119.

42. Liu NJ, von Gizycki H, Gintzler AR. Sexually Dimorphic Recruitment of Spinal Opioid Analgesic Pathways by the Spinal Application of Morphine. J Pharmacol Exp Ther. 2007;322(2):654-660.

43. Ji Y, Murphy AZ, Traub RJ. Estrogen Modulation of Morphine Analgesia of Visceral Pain in Female Rats Is Supraspinally and Peripherally Mediated. Pain. 2007;8(6):494-502.

44. Flake NM, Hermanstyne TO, Gold MS. Testosterone and estrogen have opposing actions on inflammation-induced plasma extravasation in the rat temporomandibular joint. Am J Physiol Regul Integr Comp Physiol. 2006;291(2):R343-R348.

45. Loyd DR, Sun XX, Locke EE, Salas MM, Hargreaves KM. Sex differences in serotonin enhancement of capsaicin-evoked calcitonin gene-related peptide release from human dental pulp. Pain. 2012;153(10):2061-2067.

46. Dong XD, Mann MK, Kumar U, et al. Sex-related differences in NMDA-evoked rat masseter muscle afferent discharge result from estrogen-mediated modulation of peripheral NMDA receptor activity. Neuroscience. 2007;146(2):822-832.

47. Claiborne JA, Nag S, Mokha SS. Estrogen-dependent, sex-specific modulation of mustard oil-induced secondary thermal hyperalgesia by orphanin FQ in the rat. Neurosci Lett. 2009;456(2):59-63.

48. Dina OA, Gear RW, Messing RO, Levine JD. Severity of alcoholinduced painful peripheral neuropathy in female rats: Role of estrogen and protein kinase (A and CE. Neuroscience. 2007;145(1):350-356.

49. Doyle HH, Murphy AZ. Sex differences in innate immunity and its impact on opioid pharmacology. J Neurosci Res. 2017;95(1-2):487-499.

50. Li L, Hao JX, Fredholm BB, Schulte G, Wiesenfeld-Hallin Z, Xu XJ. Peripheral adenosine A2A receptors are involved in carrageenan-induced mechanical hyperalgesia in mice. Neuroscience. 2010;170(3):923-928.

51. Bradshaw HB, Rimmerman N, Krey JF, Walker JM. Sex and hormonal cycle differences in rat brain levels of pain-related cannabimimetic lipid mediators. Am J Physiol Regul Integr Comp Physiol. 2006;291(2):R349-R358.

52. Torres-Chávez KE, Fischer L, Teixeira JM, et al. Sexual Dimorphism on Cytokines Expression in the Temporomandibular Joint The Role of Gonadal Steroid Hormones. Inflammation. 2011;34(5): 487-498.
53. Lei J, Jin L, Zhao Y, et al. Sex-related differences in descending norepinephrine and serotonin controls of spinal withdrawal reflex during intramuscular saline induced muscle nociception in rats. Exp Neurol. 2011;228(2):206-214.

54. Lacroix-Fralish ML. Sex-specific pain modulation: The growth factor, neuregulin-1, as a pro-nociceptive cytokine. Neurosci Lett. 2008;437(3):184-187.

55. Edinger KL, Frye CA. Testosterone's Analgesic, Anxiolytic, and Cognitive-Enhancing Effects May Be Due in Part to Actions of Its $5 \alpha$-Reduced Metabolites in the Hippocampus. Behav Neurosci. 2004;118(6):1352-1364.

56. Bartley EJ, Fillingim RB. Sex differences in pain: a brief review of clinical and experimental findings. Br J Anaesth. 2013;111(1):52-58.

57. Defrin R, Shramm L, Eli I. Gender role expectations of pain is associated with pain tolerance limit but not with pain threshold. Pain. 2009; $145(1): 230-236$.

58. Fillingim RB, Edwards RR. Is self-reported childhood abuse history associated with pain perception among healthy young women and men? Clin J Pain. 2005;21(5):387-397.

59. Walsh CA, Jamieson E, MacMillan H, Boyle M. Child Abuse and Chronic Pain in a Community Survey of Women. J Interpers Violence. 2007;22(12):1536-1554

60. Keogh E, Eccleston C. Sex differences in adolescent chronic pain and pain-related coping. Pain. 2006;123(3):275-284

61. Unruh AM, Ritchie J, Merskey H. Does gender affect appraisal of pain and pain coping strategies? Clin J Pain. 1999;15(1):31-40.

62. Keefe FJ, Brown GK, Wallston KA, Caldwell DS. Coping with rheumatoid arthritis pain: catastrophizing as a maladaptive strategy. Pain. 1989;37(1):51-56.

63. Forsythe LP, Thorn B, Day M, Shelby G. Race and Sex Differences in Primary Appraisals, Catastrophizing, and Experimental Pain Outcomes. Pain. 2011;12(5):563-572.

64. Bandura A. Self-efficacy: Toward a unifying theory of behavioral change. Psychol Rev. 1977;84(2):191-215.

65. Jackson T, Iezzi T, Gunderson J, Nagasaka T, Fritch A. Gender differences in pain perception: the mediating role of self-efficacy beliefs. Sex Roles. 2002;47(11/12):561-568.

66. Schwartz JB. The Influence of Sex on Pharmacokinetics. Clin Pharmacokinet. 2003;42(2):107-121.

67. Soldin OP, Mattison DR. Sex Differences in Pharmacokinetics and Pharmacodynamics. Clin Pharmacokinet. 2009;48(3):143-157.

68. Fosbøl EL, Gislason GH, Jacobsen S, et al. The pattern of use of non-steroidal anti-inflammatory drugs (NSAIDs) from 1997 to 2005: a nationwide study on 4.6 million people. Pharmacoepidemiol Drug Saf. 2008;17(8):822-833.

69. Anthony M, Lee KY, Bertram CT, et al. Gender and Age Differences in Medications Dispensed from a National Chain Drugstore. JWomens Health. 2008;17(5):735-743.

70. Isacson D, Bingefors K. Epidemiology of analgesic use: a gender perspective. Eur J Anaesthesiol Suppl. 2002;26:5-15.

71. Walker JS, Carmody JJ. Experimental pain in healthy human subjects: gender differences in nociception and in response to ibuprofen. Anesth Analg. 1998;86(6):1257-1262.

72. Compton P, Charuvastra VC, Ling W. Effect of oral ketorolac and gender on human cold pressor pain tolerance. Clin Exp Pharmacol Physiol. 2003;30(10):759-763.

73. Chillingworth NL, Morham SG, Donaldson LF. Sex differences in inflammation and inflammatory pain in cyclooxygenase-deficient mice. Am J Physiol Regul Integr Comp Physiol. 2006;291(2):R327-R334.

74. Richardson J, Holdcroft A. Gender differences and pain medication. Womens Health. 2009;5(1):79-88.

75. Sadhasivam S, Chidambaran V, Olbrecht VA, et al. Opioid-related adverse effects in children undergoing surgery: unequal burden on younger girls with higher doses of opioids. Pain Med. 2015;16(5):985-997.

76. Keers R, Aitchison KJ. Gender differences in antidepressant drug response. Int Rev Psychiatry. 2010;22(5):485-500. 
77. Sadhasivam S, Krekels EH, Chidambaran V, et al. Morphine clearance in children: Does race or genetics matter? J Opioid Manag. 2012;8(4):217-226.

78. Rowelll LN, Mechlinl B, Jil E, Addamol M, Girdlerl SS. Asians differ from non-Hispanic Whites in experimental pain sensitivity. Eur J Pain. 2011;15(7):764-771.

79. Kim HJ, Yang GS, Greenspan JD, et al. Racial and ethnic differences in experimental pain sensitivity: systematic review and meta-analysis. Pain. 2017;158(2):194-211.

80. Janicki PK. Pharmacogenomics of Pain Management. New York: Springer New York; 2015:21-31.

81. Nagasako EM, Oaklander AL, Dworkin RH. Congenital insensitivity to pain: an update. Pain. 2003;101(3):213-219.

82. Cox JJ, Reimann F, Nicholas AK, et al. An SCN9A channelopathy causes congenital inability to experience pain. Nature. 2006;444(7121):894-898.

83. Waxman SG, Dib-Hajj SD. Erythromelalgia: A hereditary pain syndrome enters the molecular era. Ann Neurol. 2005;57(6):785-788.

84. Ting S, Schug S. The pharmacogenomics of pain management: Prospects for personalized medicine. J Pain Res. 2016;9:49-56.

85. Diochot S, Baron A, Salinas M, et al. Black mamba venom peptides target acid-sensing ion channels to abolish pain. Nature. 2012;490(7421):552-555.

86. Reimann F, Cox JJ, Belfer I, et al. Pain perception is altered by a nucleotide polymorphism in SCN9A. Proc Natl Acad Sci USA. 2010;107(11):5148-5153.

87. Candiotti KA, Yang Z, Buric D, et al. Catechol-O-Methyltransferase Polymorphisms Predict Opioid Consumption in Postoperative Pain. Anesth Analg. 2014;119(5):1194-1200.

88. Diatchenko L, Nackley AG, Slade GD, et al. Catechol-O-methyltransferase gene polymorphisms are associated with multiple pain-evoking stimuli. Pain. 2006;125(3):216-224.

89. Latremoliere A, Costigan M. GCH1, BH4 and pain. Curr Pharm Biotechnol. 2011;12(10):1728-1741.

90. de Gregori M, Diatchenko L, Ingelmo PM, et al. Human Genetic Variability Contributes to Postoperative Morphine Consumption. Pain. 2016;17(5):628-636.

91. Miura Y, Mardy S, Awaya Y, et al. Mutation and polymorphism analysis of the TRKA (NTRK1) gene encoding a high-affinity receptor for nerve growth factor in congenital insensitivity to pain with anhidrosis (CIPA) families. Hum Genet. 2000;106(1):116-124.

92. Kuhnen CM, Samanez-Larkin GR, Knutson B. Serotonergic genotypes, neuroticism, and financial choices. PLOS ONE. 2013;8(1): e54632-e54632.

93. Lebe M, Hasenbring MI, Schmieder K, et al. Association of serotonin$1 \mathrm{~A}$ and -2A receptor promoter polymorphisms with depressive symptoms, functional recovery, and pain in patients 6 months after lumbar disc surgery. Pain. 2013;154(3):377-384.

94. Kapur BM, Lala PK, Shaw JLV. Pharmacogenetics of Chronic Pain Management. Clin Biochem. 2014;47(13-14):1169-1187.

95. Ciszkowski C, Madadi P, Phillips MS, Lauwers AE, Koren G. Codeine, ultrarapid-metabolism genotype, and postoperative death. $N$ Engl J Med Overseas Ed. 2009;361(8):827-828.

96. Madadi P, Koren G. Pharmacogenetic insights into codeine analgesia: implications to pediatric codeine use. Pharmacogenomics. 2008;9(9):1267-1284.

97. Madadi P, Ross CJD, Hayden MR, et al. Pharmacogenetics of Neonatal Opioid Toxicity Following Maternal Use of Codeine During Breastfeeding: A Case-Control Study. Clin Pharmacol Ther. 2009;85(1):31-35.

98. Koren G, Cairns J, Chitayat D, Gaedigk A, Leeder SJ. Pharmacogenetics of morphine poisoning in a breastfed neonate of a codeineprescribed mother. Lancet. 2006;368(9536):704.

99. Stamer UM, Musshoff F, Kobilay M, Madea B, Hoeft A, Stuber F. Concentrations of Tramadol and O-desmethyltramadol Enantiomers in Different CYP2D6 Genotypes. Clin Pharmacol Ther. 2007;82(1):41-47.

100. Stamer UM, Lehnen K, Höthker F, et al. Impact of CYP2D6 genotype on postoperative tramadol analgesia. Pain. 2003;105(1-2):231-238.
101. Kirchheiner J, Brøsen K, Dahl ML, et al. CYP2D6 and CYP2C19 genotype-based dose recommendations for antidepressants: a first step towards subpopulation-specific dosages. Acta Psychiatr Scand. 2001;104(3):173-192.

102. De Gregori S, De Gregori M, Ranzani GN, Allegri M, Minella C, Regazzi M. Morphine metabolism, transport and brain disposition. Metab Brain Dis. 2012;27(1):1-5.

103. Matic M, Norman E, Rane A, et al. Effect of UGT2B7 -900G\&gt;A (-842G\&gt;A; rs7438135) on morphine glucuronidation in preterm newborns: results from a pilot cohort. Pharmacogenomics. 2014;15(12):1589-1597.

104. Fujita K, Ando Y, Yamamoto W, et al. Association of UGT2B7 and ABCB1 genotypes with morphine-induced adverse drug reactions in Japanese patients with cancer. Cancer Chemother Pharmacol. 2010;65(2):251-258.

105. Li Y, Kantelip JP, Gerritsen-van Schieveen P, Davani S. Interindividual variability of methadone response: impact of genetic polymorphism. Mol Diagn Ther. 2008;12(2):109-124.

106. Kharasch ED, Walker A, Isoherranen N, et al. Influence of CYP3A5 genotype on the pharmacokinetics and pharmacodynamics of the cytochrome $\mathrm{P} 4503 \mathrm{~A}$ probes alfentanil and midazolam. Clin Pharmacol Ther. 2007;82(4):410-426.

107. Martínez C, Blanco G, Ladero JM, et al. Genetic predisposition to acute gastrointestinal bleeding after NSAIDs use. Br J Pharmacol. 2004;141(2):205-208.

108. Carbonell N, Verstuyft C, Massard J, et al. CYP2C9*3 Loss-of-Function Allele Is Associated With Acute Upper Gastrointestinal Bleeding Related to the Use of NSAIDs Other Than Aspirin. Clin Pharmacol Ther. 2010;87(6):693-698.

109. Pilotto A, Seripa D, Franceschi M, et al. Genetic Susceptibility to Nonsteroidal Anti-Inflammatory Drug-Related Gastroduodenal Bleeding: Role of Cytochrome P450 2C9 Polymorphisms. Gastroenterology. 2007;133(2):465-471.

110. Rosemary J, Adithan C. The pharmacogenetics of CYP2C9 and CYP2C19: ethnic variation and clinical significance. Curr Clin Pharmacol. 2007;2(1):93-109.

111. Visser LE, van Schaik RH, van Vliet M, et al. Allelic variants of cytochrome P450 2C9 modify the interaction between nonsteroidal anti-inflammatory drugs and coumarin anticoagulants. Clin Pharmacol Ther. 2005;77(6):479-485.

112. Sadhasivam S, Chidambaran V, Zhang X, et al. Opioid-induced respiratory depression: ABCB1 transporter pharmacogenetics. Pharmacogenomics J. 2015;15(2):119-126.

113. Park HJ, Shinn HK, Ryu SH, Lee HS, Park CS, Kang JH. Genetic polymorphisms in the ABCB1 gene and the effects of fentanyl in Koreans. Clin Pharmacol Ther. 2007;81(4):539-546.

114. Kesimci E, Engin AB, Kanbak O, Karahalil B. Association between ABCB1 gene polymorphisms and fentanyl's adverse effects in Turkish patients undergoing spinal anesthesia. Gene. 2012;493(2): 273-277.

115. Tzvetkov MV, dos Santos Pereira JN, Meineke I, Saadatmand AR, Stingl JC, Brockmöller J. Morphine is a substrate of the organic cation transporter OCT1 and polymorphisms in OCT1 gene affect morphine pharmacokinetics after codeine administration. Biochem Pharmacol. 2013;86(5):666-678.

116. Landau R, Kern C, Columb MO, Smiley RM, Blouin JL. Genetic variability of the mu-opioid receptor influences intrathecal fentanyl analgesia requirements in laboring women. Pain. 2008;139(1):5-14.

117. Fillingim RB, Kaplan L, Staud R, et al. The A118G single nucleotide polymorphism of the mu-opioid receptor gene (OPRM1) is associated with pressure pain sensitivity in humans. J Pain. 2005;6(3):159-167.

118. Hayashida M, Nagashima M, Satoh Y, et al. Analgesic requirements after major abdominal surgery are associated with OPRM1 gene polymorphism genotype and haplotype. Pharmacogenomics. 2008;9(11):1605-1616.

119. Janicki PK, Schuler G, Francis D, et al. A genetic association study of the functional $\mathrm{A} 118 \mathrm{G}$ polymorphism of the human mu-opioid receptor gene in patients with acute and chronic pain. Anesth Analg. 2006;103(4):1011-1017. 
120. Mogil JS, Ritchie J, Smith SB, et al. Melanocortin-1 receptor gene variants affect pain and mu-opioid analgesia in mice and humans. $J$ Med Genet. 2005;42(7):583-587.

121. Lee YS, Kim H, Wu TX, Wang XM, Dionne RA. Genetically mediated interindividual variation in analgesic responses to cyclooxygenase inhibitory drugs. Clin Pharmacol Ther. 2006;79(5):407-418.

122. Reyes-Gibby $\mathrm{CC}$, Shete $\mathrm{S}$, Rakvåg $\mathrm{T}$, et al. Exploring joint effects of genes and the clinical efficacy of morphine for cancer pain: OPRM1 and COMT gene. Pain. 2007;130(1-2):25-30.

123. Rakvåg TT, Klepstad $\mathrm{P}$, Baar C, et al. The Val158Met polymorphism of the human catechol-O-methyltransferase (COMT) gene may influence morphine requirements in cancer pain patients. Pain. 2005;116(1-2):73-78.

124. Sadhasivam S, Chidambaran V, Olbrecht VA, et al. Genetics of pain perception, COMT and postoperative pain management in children. Pharmacogenomics. 2014;15(3):277-284.

125. Sheets PL, Jackson JO, Waxman SG, Dib-Hajj SD, Cummins TR. A Nav1.7 channel mutation associated with hereditary erythromelalgia contributes to neuronal hyperexcitability and displays reduced lidocaine sensitivity. J Physiol. 2007;581(Pt 3):1019-1031.

126. Vernooy K, Sicouri S, Dumaine R, et al. Genetic and biophysical basis for bupivacaine-induced ST segment elevation and VT/VF. Anesthesia unmasked Brugada syndrome. Heart Rhythm. 2006;3(9):1074-1078.

127. Ko TM, Wong CS, Wu JY, Chen YT. Pharmacogenomics for personalized pain medicine. Acta Anaesthesiol Taiwan. 2016;54(1):24-30.

128. Mccormack M, Alfirevic A, Bourgeois S, et al. HLA-A*3101 and carbamazepine-induced hypersensitivity reactions in Europeans. $N$ Engl J Med. 2011;364(12):1134-1143.

129. Li X, Yu K, Mei S, et al. HLA-B*1502 increases the risk of phenytoin or lamotrigine induced Stevens-Johnson Syndrome/toxic epidermal necrolysis: evidence from a meta-analysis of nine case-control studies. Drug Res. 2015;65(2):107-111.
130. Hung SI, Chung WH, Liu ZS, et al. Common risk allele in aromatic antiepileptic-drug induced Stevens-Johnson syndrome and toxic epidermal necrolysis in Han Chinese. Pharmacogenomics. 2010;11(3):349-356.

131. Chen P, Lin JJ, Lu CS, et al. Carbamazepine-induced toxic effects and HLA-B*1502 screening in Taiwan. N Engl J Med. 2011;364(12): 1126-1133.

132. Crews KR, Gaedigk A, Dunnenberger HM, et al. Clinical Pharmacogenetics Implementation Consortium (CPIC) guidelines for codeine therapy in the context of cytochrome P450 2D6 (CYP2D6) genotype. Clin Pharmacol Ther. 2012;91(2):321-326.

133. Viet CT, Dang D, Ye Y, Ono K, Campbell RR, Schmidt BL. Demethylating drugs as novel analgesics for cancer pain. Clin Cancer Res. 2014;20(18):4882-4893.

134. Tochiki KK, Cunningham J, Hunt SP, Géranton SM. The expression of spinal methyl-CpG-binding protein 2, DNA methyltransferases and histone deacetylases is modulated in persistent pain states. Mol Pain. 2012;8:14.

135. Bai G, Wei D, Zou S, Ren K, Dubner R. Inhibition of class II histone deacetylases in the spinal cord attenuates inflammatory hyperalgesia. Mol Pain. 2010;6:51.

136. Agrawal RP, Goswami J, Jain S, Kochar DK. Management of diabetic neuropathy by sodium valproate and glyceryl trinitrate spray: a prospective double-blind randomized placebo-controlled study. Diabetes Res Clin Pract. 2009;83(3):371-378.

137. Handy CR, Krudy C, Boulis N. Gene therapy: a potential approach for cancer pain. Pain Res Treat. 2011;2011:987597.

138. Fink DJ, Wechuck J, Mata M, et al. Gene therapy for pain: results of a phase I clinical trial. Ann Neurol. 2011;70(2):207-212.

139. Trescot AM, Faynboym S. A review of the role of genetic testing in pain medicine. Pain Physician. 2014;17(5):425-445.
Journal of Pain Research

\section{Publish your work in this journal}

The Journal of Pain Research is an international, peer reviewed, open access, online journal that welcomes laboratory and clinical findings in the fields of pain research and the prevention and management of pain. Original research, reviews, symposium reports, hypothesis formation and commentaries are all considered for publication.

\section{Dovepress}

The manuscript management system is completely online and includes a very quick and fair peer-review system, which is all easy to use. Visit http://www.dovepress.com/testimonials.php to read real quotes from published authors. 